\title{
DEVELOPING A CONCEPTUAL MODEL FOR VALUE DELIVERY IN VALUE SHOP CONFIGURED CONSTRUCTION PROJECTS
}

\author{
Frode Drevland $^{1}$ and Ole Jonny Klakegg ${ }^{2}$
}

\begin{abstract}
Value configuration is a term from the business literature that describes how companies are rigged for delivering value. The paper argues that modern day construction projects adheres to a value shop configuration rather than a value chain configuration. Where the focus of the value chain is the transformation of inputs into products, the focus of the value shop is to (re)solve customer problems.

The main theoretical foundation of Lean Construction for understanding value delivery is the Transformation-Flow-Value (TFV) theory of production. While this provides a solid basis and model for understanding value delivery in value chain configured construction projects, it comes up short with regards to value shop configured projects.

The paper presents a newly developed conceptual model for the value delivery in value shop configured construction projects, and shows how it can be beneficial vis-à-vis the TFV theory with regards to understanding the fundamentals of value delivery in value shop configured construction projects
\end{abstract}

\section{KEYWORDS}

Lean construction, theory, value delivery

\section{INTRODUCTION}

In the last few decades there has also been a shift in focus of project management from just delivering scope on time and on budget to delivering value (Laursen and Svejvig 2016). Within Lean Construction, value has always been central. However the topic of value is not without issues. While there is no contention that the goal of projects is to deliver value (Emmitt et al. 2005), there is no agreement of what value is (Drevland et al. 2017a; Salvatierra-Garrido et al. 2010) or whom we should deliver value to (Drevland and Tillmann 2018). We would argue that the fundamentals of value delivery in modern day construction projects is poorly understood. Furthermore. we would argue this is at least partially due to not having s suitable conceptual model of value delivery.

1 Assistant Professor, NTNU - Norwegian University of Science and Technology, Trondheim, Norway, +4792064 262, frode.drevland@ntnu.no

2 Professor, NTNU - Norwegian University of Science and Technology, Trondheim, Norway, ole.jonny.klakegg@ntnu.no 
In general, models represent reality in some way or form (Gregory 1993; Meredith 1993). Models can have different levels of abstraction. On one end of the scale we find iconic models, which are physical representations of objects or systems, such as scale models. In these, there is a one-to-one relationship between every part of the model and the real object or system it represents. On the other end of the scale we find pure conceptual models, where the elements of such models do not necessarily have a real-world equivalent (Gregory 1993).

While the literature is ambiguous with regards to what constitutes a conceptual model, we defer to Greca and Moreira (2000) 's definition. According to them, a conceptual model is an "external representation created by researchers, teachers, engineers, etc., that facilitates the comprehension or the teaching of systems or states of affairs in the world".

The literature contains little in the way of conceptual models of the value delivery process that takes place in projects. What exists on the subject mostly falls into one of two categories; 1) those that treat projects as a black box and 2) those that are very closely tied to specific tools and models such as Value Management (e.g. Kelly 2007). The one notable exception is Koskela's seminal Transformation-Flow-Value (TFV) theory of production, which is a cornerstone of the LC theoretical body of knowledge. However, we will in this paper argue that the TFV-theory is inadequate for fully understanding value delivery for the value configuration that modern construction projects employ.

Value configuration is a term from the business literature used to explain how companies are rigged with regards to delivering value to their customers. Following the method section, the paper starts by introducing the concept, and the different archetypes of value configuration, in detail and contextualising it for construction projects. Next, we give a brief overview of the TFV-theory and present arguments for it being inadequate for fully describing value delivery in construction projects. Thereafter, we present a new conceptual model for the value delivery in construction projects. Finally, we discuss the model's aptness versus the TFV-theory.

\section{METHOD}

This paper is anchored in the pragmatic research paradigm. This paradigm "sidesteps the contentious issues of truth and reality, accepts, philosophically, that there are singular and multiple realities that are open to empirical inquiry and orients itself toward solving practical problems in the "real world" (Feilzer 2010). Within the pragmatic paradigm "inquiry aims at utility for us rather than an accurate account of how things are in themselves", and truth is here seen as a matter of useful belief (Rorty 1999).

The conceptual model presented later in this paper has been developed through abductive reasoning. Abduction is an alternative form of inference to the more traditional induction and deduction. The term was first coined by the pragmatist philosopher Charles Sanders Peirce (Burks 1946). Pierce refers to it as the logic of discovery, the only logic that can truly create new theoretical knowledge (Peirce et al. 1994). 


\section{VALUE CONFIGURATION}

In his seminal book Competitive Advantage: Creating and Sustaining Superior Performance, Porter (1985) introduced the concept of value chain, which he describes as a representation of the collection of activities that are performed in a company to design, produce, market and deliver the company's product.

Porter argues that the general value-creating logic of the value chain model is valid for all industries. This notion is challenged by Stabell and Fjeldstad (1998), who argue that the value chain concept has several shortcomings with regards to describing the value creation taking place in many companies. One of their examples is that of banks:

"Our experience is that value chain analysis frequently results in either postulating deposits as the 'raw material' that the bank's primary activities transform into loans, or postulating that all primary banking activities collapse into a single major activity class: operations. In either case, the chain model cannot deal explicitly with both lenders and borrowers as bank customers. The

value chain metaphor obscures the competitive logic of banking by focusing attention on transaction-processing unit costs, with little attention to interest spread and risk management."

Stabell and Fjeldstad (1998) further argue that the value chain is but one of three generic value configurations. The other two being value shop and value network. The attributes of each of the three models are summarized in Table 1. While these value configurations are intended to describe how value is created in companies, we would argue that they are also applicable for describing projects as value delivery systems.

Value network configured companies deliver value linking their customers together, for example, telecommunication providers. For construction projects, there are no analogue to this. However, we would argue that the other two configurations have analogous project delivery models.

The value delivery logic of traditional project management and traditional design-bidbuild delivery resembles the logic of the value chain. The scope is locked at the outset of the project, and optimisation is matter minimising inputs in delivering this output. Conversely, modern project delivery approaches, such as Lean Integrated Project Delivery, are more open ended at the outset and focused on fulfilling the client's purpose rather than delivering a locked scope. We would argue that such delivery models can be considered to be value shop configured. 
Table 1 Overview of alternative value configurations (Stabell and Fjeldstad 1998)

\begin{tabular}{|c|c|c|c|}
\hline & Chain & Shop & Network \\
\hline Value creation logic & $\begin{array}{l}\text { Transformation of } \\
\text { inputs into products }\end{array}$ & $\begin{array}{c}(\mathrm{Re}) \text { solving customer } \\
\text { problems }\end{array}$ & Linking customers \\
\hline Primary technology & Long-linked & Intensive & Mediating \\
\hline Primary activity & $\begin{array}{ll}\text { - } & \text { Inbound } \\
\text { logistics } \\
\text { - } & \text { Operations } \\
\text { - } & \text { Outbound } \\
& \text { logistics } \\
\text { - } & \text { Marketing } \\
\text { - } & \text { Service }\end{array}$ & $\begin{array}{ll}\text { - } & \text { Problem- } \\
\text { finding and } \\
\text { acquisition } \\
\text { - } & \text { Problem- } \\
\text { solving } \\
\text { - } & \text { Choice } \\
\text { - } & \text { Execution } \\
\text { - } & \text { Control } \\
& \text { evaluation }\end{array}$ & $\begin{array}{l}\text { - } \\
\text { promotwork } \\
\text { contract } \\
\text { management } \\
\text { - } \quad \text { Service } \\
\text { provisioning } \\
\text { - Infrastructure } \\
\text { operation }\end{array}$ \\
\hline $\begin{array}{l}\text { Main interactivity } \\
\text { relationship logic }\end{array}$ & Sequential & Cyclical, spiralling & Simultaneous, parallel \\
\hline $\begin{array}{l}\text { Primary activity } \\
\text { interdependence }\end{array}$ & $\begin{array}{ll}\text { - } & \text { Pooled } \\
\text { - } & \text { Sequential }\end{array}$ & $\begin{array}{ll}\text { - } & \text { Pooled } \\
\text { - } & \text { Sequential } \\
\text { - } & \text { Reciprocal }\end{array}$ & $\begin{array}{ll}\text { - } & \text { Pooled } \\
\text { - } & \text { reciprocal }\end{array}$ \\
\hline Key cost drivers & $\begin{array}{ll}\text { - } & \text { Scale } \\
\text { - } & \text { Capacity } \\
& \text { utilization }\end{array}$ & & $\begin{array}{ll}\text { - } & \text { Scale } \\
\text { - } & \text { Capacity } \\
& \text { utilization }\end{array}$ \\
\hline Key value drivers & & - Reputation & $\begin{array}{ll}\text { - } & \text { Scale } \\
\text { - } & \text { Capacity } \\
& \text { utilization }\end{array}$ \\
\hline $\begin{array}{l}\text { Business value } \\
\text { system structure }\end{array}$ & $\begin{array}{l}\text { - Interlinked } \\
\text { chains }\end{array}$ & 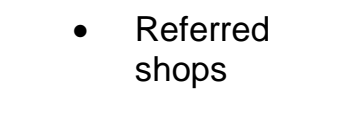 & $\begin{array}{l}\text { - Layered and } \\
\text { interconnected } \\
\text { networks }\end{array}$ \\
\hline
\end{tabular}

\section{THE TRANSFORMATION-FLOW-VALUE THEORY}

According to Koskela (2000), three different conceptualisations of production have been present through the 20th century have been used. He argues that all three are needed and synthesises them to one common theory; the Transformation-Flow-Value (TFV) theory.

The predominant conceptualisation of production has historically been that of a transformation of inputs to outputs. Here, it is assumed that the overall transformation can 
be decomposed into a set of smaller transformations, which in turn can be optimised to improve the whole.

One limitation of the transformation conceptualisation is that it only considers where processing takes place, i.e. the value-adding activities. If a production process is decomposed into smaller transformation activities, then this decomposition will also yield several non-value-adding activities in between, such as transportation, inspection and waiting. This is the focus of the second conceptualisation, flow, which considers production processes as flows of materials and resources. Flow activities - or non-value adding activities - are considered waste and are sought to be minimised or eliminated.

Another flaw of the transformation conceptualisation is that it is prone to suboptimisation. Neither consequences on downstream operations nor the qualities of the final product are of concern when optimising the smaller tasks. This is the domain of the third conceptualisation, value, which is concerned with the realisation of the customers (internal and external) needs.

\section{CRITIQUE OF THE TFV-THEORY}

Winch (2006) provides a thorough critique of the TFV-theory. Of special interest is his critique of the unitary value concept implied in the TFV theory, with the focus being solely on the final customer. Winch argues that there are three different value aspects that must be considered:

1. the contribution that the asset created by the process makes to the client's business processes

2. the contribution that the process makes to the supplier's business processes

3. the contribution that the asset makes to society as a whole

Drevland and Tillmann (2018) have argued that there might be even more groups that must be considered, than those who Winch (2006) mention. However, Winch's view is in line with the arguments by Drevland and Tillmann. The salient point here is that the projects as value delivery systems must take into account the value for more than one customer at once.

The TFV-theory does to some extent consider multiple customers. All downstream workstations are considered customers, and the value for those should always be considered. However, the value measurement and optimisation that takes place is always related to the final customer. I.e. better value delivered to a downstream workstation is only interesting insofar as it improves the value delivered to the final customer.

We would argue that the TFV-theory is excellent for explaining and optimising production in cases where the output, that the production system should deliver, is fixed at the outset. E.g. assembly lines or traditionally scope locked projects. However, we would furthermore argue that it comes up short for any project model that can be considered a value shop configuration.

In the TFV-theory, the value to be delivered is simply equated to be what the customer wants in terms of hard requirements. These requirements will be formulated based on some perception of what is valuable at that point in time. Herein lies the problem. The perception of this will be dependent on both the context and the knowledge of the customer (Drevland et al. 2017a). Construction can take a significant time to complete, and the changes in the 
customer's context could be significant during that time. Furthermore, knowledge can be said to be the key product of any design process (Reinertsen 1997) Thus; the customer's perception will change as the project moves forward and new knowledge is gained. Modern project delivery models, typically integrating design and construction, therefore requires value to be treated dynamically.

Another issue with the TFV theory is that at the core it is a linear model. While it is well suited for a value chain configuration, which has sequential logic, it is not so much so for a value shop configuration, where the main interactivity logic in a value shop configuration is cyclical or spiralling. We would argue that a conceptual model of the value delivery process, of value shop configured projects, should not be purely linear, but rather should have some notion of iterativity.

\section{THE STAKEHOLDER VALUE DELIVERY MODEL}

This section presents the Stakeholder-Value-Delivery (SVD) model. The model, shown in Figure 2 is heavily inspired and influenced by Gero's (1990) Function-BehaviourStructure model of design. However, the model is too fundamentally different to say that it is derived from it.

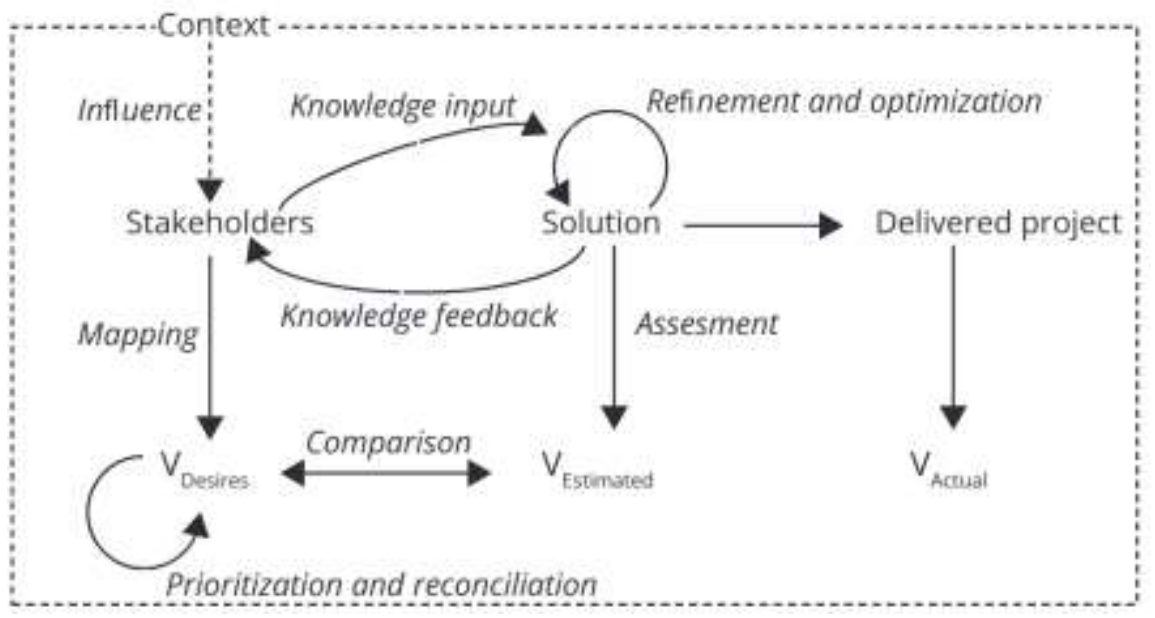

Figure 1 The Stakeholder Value Delivery Model

\section{Stakeholders}

Exactly who's value matters in a project is a matter of philosophy (Drevland and Tillmann 2018). However, in general, the goal of any project will be to deliver value to a set of stakeholders. The project, when delivered, will yield $V_{\text {Actual }}$, this being the set of value actually delivered to each stakeholder. The project delivery process then becomes a matter of finding and executing a Solution that will lead to $V_{\text {Actual }}$ being maximised.

Since $V_{\text {Actual }}$ is the set of value for all stakeholder, and there always some degree of value misalignment between these, maximising must necessarily be in accordance to some value philosophy. It is impossible to maximise the value for all stakeholders at once.

According to Drevland et al. (2017a), there are three elements that come into play for a stakeholders perception of value 1) their values, 2) their context, and 3) their knowledge. 
While peoples values can and do change, especially when dealing with money (DeScioli et al. 2014), we would argue that stakeholders changing values is not a typical nor expected result of the value delivery process. Furthermore, insofar as they do, this can be said to be as a function of new knowledge received from the solution. Similarly, any change in values caused by something outside of the project can be said to be a matter of a changing context. Values, as such, are therefore not an element of the model.

\section{Context influence}

Every stakeholder and the project is surrounded by a context. This context influences the stakeholders' perception of value and the value they desire from the delivered project. For example, hospital projects take a long time to complete. During the project execution, several contextual factors could come into play, such as developments in medical technology or demographic shifts, that would change how the owner would want the final design of the facility.

\section{Mapping}

The starting point of the solution process will be an understanding of what is valuable $V_{\text {Desires}}$, for the different stakeholders. In the literature, explicit processes that are undertaken to understand stakeholder value are typically referred to as elicitation (Barney et al. 2008; Boehm 2006; Grünbacher et al. 2006; Niazi et al. 2006). The SVD model, however, refers to processes that help form this understanding as mapping. Partially, because this understanding is not necessarily formed by any explicit elicitation. It could, for example, be formed in part by assumptions and general knowledge. Also, because someone's understanding of what is valuable versus what actually is valuable is analogous to a map and the terrain it represents.

\section{Prioritisation and reconciliation}

For many projects, especially large buildings and infrastructure projects, there are many stakeholders, and there will inevitably be value misalignments between some of them (Drevland et al. 2017b). In such cases, some sort of prioritisation and reconciliation processes must take place. These could be formal and explicit, or they might be informal and subconscious. However, at some level, somehow, such processes must necessarily take place.

\section{Solution}

Given that some notion of $V_{\text {Desires }}$, i.e. what is of value for the different stakeholder, formulating a solution that achieves the desired value can be attempted. The form and content of the solution will vary wildly, depending on where we are in the project life cycle. From a pure cost model in early stages to full-blown set of design drawings, execution plans, installation instructions and such in the final stages.

\section{Refinement and optimisation}

The solution is iterated on either through refinement or optimisation. We define refinement as taking the solution further forward, i.e. adding elements or details that have so far been abstracted away. Furthermore, we define optimisation as improving the solution at the level that it is. Both refinement and optimisation can be conceptualised as a process of 
identifying, developing and selecting solution alternatives, as illustrated in Figure 2. There is one key difference. For optimisation, one on the alternatives will be the existing solution and some evaluation of whether iterating on this solution will be worthwhile, i.e. that the expected marginal improvement of the solution outweighs the expected cost of doing the optimisation.

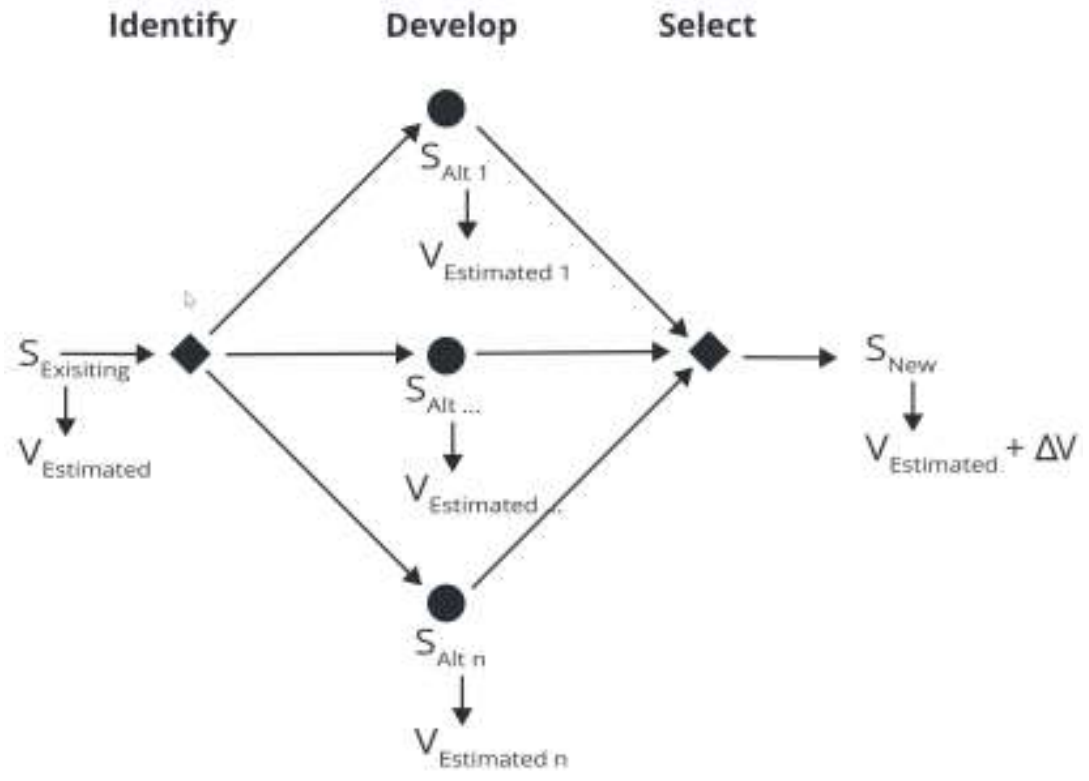

Figure 2 Process of refining or optimising solution

\section{Assessment}

The choices that are made during refinement or optimisation will be based on some notion of which alternative yields the most value. $V_{\text {Estimated }}$ is the estimate of what value the solution will give. The solution will typically be expressed in terms that are not directly relatable to $V_{\text {Desires. }}$. For example, a hospital owner will desire a building that is cheap to build and maintain, and fit for purpose, while the design of the building is threedimensional arrangement of materials and building elements. Thus, assessment categorises any processes related to estimating the impact of the elements that are contained in $V_{\text {Desires }}$.

\section{Comparison}

Based on a comparison between $V_{\text {Desires }}$ and $V_{\text {Estimated }}$ the goodness of the solution can be assessed. The results of this comparison will feed into the decision to further refine and/or optimise, as well as setting the target for these processes.

\section{Knowledge Input and Knowledge Feedback}

Coming up with the solution requires knowledge possessed by the stakeholders. Those that will design and build the project, as well as those that will own and use it. However, there is also a feedback loop here. The solution process creates knowledge which feeds back to the stakeholders. The perception of value being dependent on knowledge, entails that what 
is seen as valuable might now have shifted. Thus, ideally the map should then be updated to how the terrain is currently observed.

\section{DISCUSSION AND CONCLUSION}

We have in this paper made the case that projects using modern project delivery models should be considered value shop configured. However, this is a somewhat simplistic view that we would argue would not hold up well when faced with reality and the immensely complex nature of construction projects. There are certain aspects of any project, regardless of delivery model, that would benefit from being optimised either through a value chain lens or through a value shop lens. While traditional projects can be said to heavily value shop configured in the execution phase, the early phase will still focus on problem-solving. Conversely, while the problem-solving stretches further out in modern project delivery models, at some point in time, what is to be built will be locked down, and the construction process can be considered sequential.

The TFV-theory provides an excellent foundation for analysing and optimising projects through a value chain lens, but it is ill-suited to do the same when regarding projects through a value shop lens. We propose that the SVD-model presented in this paper can fill that role. Thus, we would argue that the TFV-theory and the SVD-model are complementary rather than competing conceptual models of project value delivery.

Is the SVD-model a good representation of the value delivery process in value shop configured projects? Considering that we are operating within a pragmatic research paradigm, where truth is a matter of useful belief, the question is not whether the model can be said to be a truthful representation of reality in the positivist sense, but rather if it is useful. This question cannot be can fully answered here but is something that must be left to future research. We can allude to how it can have some explanatory powers versus the TFV theory.

A feature of some the most successful tools used in Lean Construction is that they have very fast feedback cycles with regards to the SVD-model loop. Some could even be considered integrated process in the sense that Mapping, Prioritisation and Reconciliation, Knowledge Transfer, Solution and Optimisation, and Assessment are all performed by the same people in in very rapid feedback setting. One example of this is the 3P method which involves getting key stakeholders together and building full-scale mock-ups of facilities, typically using cardboard and tape, and simulating their use. Other examples are Choosing by Advantages for decision making and pull planning for scheduling.

While the TVF-theory can to some extent be used to describe the effects of the use of such tools, it does not have the vocabulary or constructs to explain the fundamental mechanisms that they act upon. The SVD-model on the other hand does. We would argue that this is essential to have these if we want to go beyond the incremental improvements of trial and error, when it comes improving such tools or developing new tools to replace them. 


\section{REFERENCES}

Barney, S., Aurum, A., and Wohlin, C. (2008). "A product management challenge: Creating software product value through requirements selection." Journal of Systems Architecture, Selection of best papers from the 32nd EUROMICRO Conference on 'Software Engineering and Advanced Applications' (SEAA 2006), 54(6), 576-593.

Boehm, B. W. (2006). "Value-Based Software Engineering: Seven Key Elements and Ethical Considerations." Value-Based Software Engineering, Springer, Berlin, Heidelberg, 109-132.

Burks, A. W. (1946). "Peirce's Theory of Abduction.” Philosophy of Science, 13(4), 301306.

DeScioli, P., Massenkoff, M., Shaw, A., Petersen, M. B., and Kurzban, R. (2014). "Equity or equality? Moral judgments follow the money." Proceedings of the Royal Society B: Biological Sciences, 281(1797).

Drevland, F., Lohne, J., and Klakegg, O. J. (2017a). "Defining and ill-defined concept: Nine tenets on the nature of value." Lean Construction Journal.

Drevland, F., Lohne, J., and Klakegg, O. J. (2017b). "Ethical Dilemmas in Value Delivery: Theoretical Conditions." 25th Annual Conference of the International Group for Lean Construction, Heraklion, Greece, 145-152.

Drevland, F., and Tillmann, P. A. (2018). "Value for Whom?" 26th Annual Conference of the International Group for Lean Construction, Chennai, India, 261-270.

Emmitt, S., Sander, D., and Christoffersen, A. K. (2005). "The Value Universe: Defining a Value Based Approach to Lean Construction." 13th Ann. Conf. of the Int'l. Group for Lean Construction, Sydney, Australia.

Feilzer, M. Y. (2010). "Doing Mixed Methods Research Pragmatically: Implications for the Rediscovery of Pragmatism as a Research Paradigm." Journal of Mixed Methods Research, 4(1), 6-16.

Gero, J. S. (1990). "Design prototypes. A knowledge representation schema for design." AI Magazine, 11(4), 26-36.

Greca, I. M., and Moreira, M. A. (2000). "Mental models, conceptual models, and modelling." International Journal of Science Education, 22(1), 1-11.

Gregory, F. (1993). "Cause, Effect, Efficiency and Soft Systems Models." The Journal of the Operational Research Society, 44(4), 333-344.

Grünbacher, P., Köszegi, S., and Biffl, S. (2006). "Stakeholder Value Proposition Elicitation and Reconciliation." Value-Based Software Engineering, Springer, Berlin, Heidelberg, 133-154.

Kelly, J. (2007). "Making client values explicit in value management workshops." Construction Management and Economics, 25(4), 435-442.

Koskela, L. (2000). "An exploration towards a production theory and its application to construction.” Helsinki University of Tehchnology, Espoo.

Laursen, M., and Svejvig, P. (2016). "Taking stock of project value creation: A structured literature review with future directions for research and practice." International Journal of Project Management, 34(4), 736-747.

Meredith, J. (1993). "Theory Building through Conceptual Methods." International Journal of Operations \& Production Management, 13(5), 3-11. 
Niazi, M., Cox, K. A., and Verner, J. M. (2006). "An Empirical Study Identifying High Perceived Value Requirements Engineering Practices." Advances in Information Systems Development, Springer, Boston, MA, 731-743.

Peirce, C. S., Hartshorne, C., Weiss, P., and Burks, A. W. (1994). The collected papers of Charles Sanders Peirce. InteLex Past Masters, InteLex Corporation, Charlottesville, Va.

Porter, M. E. (1985). Competitive Advantage: Creating and Sustaining Superior Performance. Free Press.

Reinertsen, D. G. (1997). Managing the Design Factory. Free Press.

Rorty, R. (1999). Philosophy and Social Hope. Penguin.

Salvatierra-Garrido, J., Pasquire, C., and Thorpe, T. (2010). "Critical review of the concept of value in lean construction theory." 18th Ann. Conf. of the Int'l. Group for Lean Construction, 33-41.

Stabell, C. B., and Fjeldstad, Ø. D. (1998). "Configuring value for competitive advantage: on chains, shops, and networks." Strategic Management Journal, 19(5), 413-437.

Winch, G. M. (2006). "Towards a theory of construction as production by projects." Building Research \& Information, 34(2), 154-163. 
Drevland, F. and Klakegg O.J.

1402

Proceedings IGLC - 27, July 2019, Dublin, Ireland 